\title{
Patent foramen ovale and closure of patent foramen ovale in patients with cryptogenic stroke
}

\section{Sandra Makarović*}

University Hospital Centre Osijek, Osijek, Croatia
RECEIVED:

February 28, 2019

ACCEPTED:

March 24, 2019

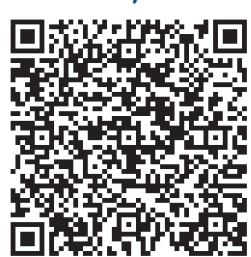

KEYWORDS: patent foramen ovale, closure, stroke.

CITATION: Cardiol Croat. 2019;14(3-4):67. | https://doi.org/10.15836/ccar2019.67

*ADDRESS FOR CORRESPONDENCE: Sandra Makarović, Klinički bolnički centar Osijek, Ul. Josipa Huttlera 4, HR31000, 0sijek, Croatia. / Phone: +385-31-511-511 / E-mail: sandramakarovic@yahoo.com

ORCID: Sandra Makarović, https://orcid.org/0000-0002-7487-1189

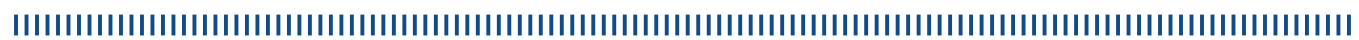

The patent foramen ovale (PFO) is a common anatomical variant in humans (prevalence 25\%). Most common asymptomatic (incidental), it can be a cause of a paradoxical embolic stroke. A dedicated PFO occluder (Amplatzer PFO Occluder) was first used in 1997. Since, it has been used often as common and safe procedure. Three randomized studies (Randomized Evaluation of Recurrent Stroke Comparing PFO Closure to Established Current Standard of Care Treatment-RESPECT, Closure or medical therapy for cryptogenic stroke with patent foramen ovale-CLOSURE, Patent Foramen Ovale Closure or Antiplatelet Therapy for Cryptogenic Stroke-REDUCE), have proved its benefit for prevention of recurrent ischemic events (most commonly stroke), in patients without conventional stroke pathology. ${ }^{1-3}$

We present a series of cases of young people, with cryptogenic stoke, PFO demonstrated on transesophageal echocardiography, using "bubbles" study, and successful transesophageal guided closure of PFO. Prior to PFO closure, a structured and systematic approach allows for a rapid and comprehensive echocardiographic assessment of the atrial septum. Good echocardiographic assessment of the atrial septal anatomy before closure is of paramount importance to allow the procedure to remain safe and effective.
LITERATURE IIIIIIIIIIIIIIIIIIIIIIIIIIIIIIIIIIIIIIIIIIIIIIIIIIIIIIIIIIIIIIIIIIIIIIIIIIIIIIIIIIIIIIIIIIIIIIIIIIIIII

1. Van Camp G, Franken P, Melis P, Cosyns B, Schoors D, Vanoverschelde JL. Comparison of transthoracic echocardiography with second harmonic imaging with transesophageal echocardiography in the detection of right to left shunts. Am J Cardiol. 2000 Dec 1;86(11):1284-7, A9. https://doi.org/10.1016/s0002-9149(00)01224-8

2. Putaala J, Metso AJ, Metso TM, Konkola N, Kraemer Y, Haapaniemi E, et al. Analysis of 1008 consecutive patients aged 15 to 49 with first-ever ischemic stroke: the Helsinki young stroke registry. Stroke. 2009 Apr;40(4):1195-203. https://doi.org/10.1161/STROKEAHA.108.529883

3. American College of Cardiology [Internet]. Randomized Evaluation of Recurrent Stroke Comparing PFO Closure to Established Current Standard of Care Treatment - RESPECT. Available from: https://www.acc.org/latest-in-cardiology/Clinical-trials/2013/07/19/12/28/respect [cited 2017 Mar 20]. 